Fourth International Conference on Sustainable Construction Materials and Technologies http://www.claisse.info/Proceedings.htm

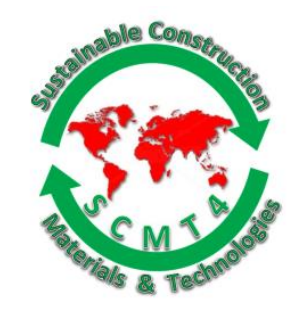

SCMT4

Las Vegas, USA, August 7-11, 2016

\title{
Mechanical and Thermal Insulation Properties of High Volume Fly Ash Fiber Reinforced Cement Composite (HVFA-FRCC) Manufactured by Extrusion Technique
}

\author{
Hamed Mokhtari Amir Majdi*1a, Zongjin LI ${ }^{1 b}$ \\ ${ }^{l}$ Department of Civil and Environmental Engineering ,The Hong Kong University of Science and

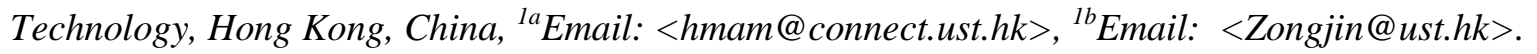

\begin{abstract}
As sustainability issue moves to the forefront of construction and building industry, utilizing waste materials for partial replacement of Portland cement and consequently decreasing $\mathrm{Co} 2$ emission has received much more attention. This study presents thermal insulation and mechanical properties of high volume fly ash fiber reinforced cement composite (HVFA-FRCC) manufacture by extrusion. The objective of this study is to improve thermal insulation properties of high volume fly ash fiber reinforced cement composite with acceptable mechanical properties to be used for building façade. Paraffin (PA) as an organic phase change material(PCM) was directly incorporated into porous structure of expanded perlite (EP) as light weight aggregate and formed PCM composite.TGA (thermo gravimetric analysis) results revealed the PCM composite is stable in the outdoor environment temperature. Steady thermal test showed that incorporation of PCM composite in the extruded panels enhances temperature differences between inner and outer surfaces of panel indicating that PCM is effective for thermal energy storage purpose. Moreover, extrusion technique improves flexural toughness of panels in spite of reduction of flexural strength in PCM incorporated specimens due to dilution of matrix by phase change materials. Our studies showed that HVFA extruded fiber reinforced cement composites with phase change material has a great potential to be used as building façade due to its high energy storage property as well as using waste materials which makes it a sustainable construction material.
\end{abstract}

\section{INTRODUCTION}

Cementitious materials and concrete have been used since thousands of years by mankind. The oldest archaeological finds of concrete date back to about 5,600 B.C. [Bhatty 2004]. Today, Portland cement based concrete is the most used solid materials. In 2014, it has been estimated that $4.18 \mathrm{Gt}$ cement were produced world-wide [USGS 2015]. Depending on the production process and fuel used, producing of 1 ton Portland cement clinker releases around 0.7-1 ton $\mathrm{CO}_{2}$ to the atmosphere.Consequently, there is huge concern about reducing greenhouse gases in cement industry. There are different possibilities to reduce carbon dioxide in cement industry. One way is to optimize grinding process and heat transfer in the kiln. This solution, however, does not yield in much reducing $\mathrm{CO}_{2}$ emission since the new applied technologies cannot 
dramatically improve energy efficiency [Gartner 2004, Damtoft 2008]. Another way to reduce $\mathrm{CO}_{2}$ emission during cement production process is the replacement of Portland cement by supplementary cementitious materials which are either extracted from natural resources like limestone powder and clay or from industrial by-products like fly ash, silica fume and metallurgical slags.

Casting and pressing as two traditional technologies for manufacturing cement based materials have their own limitations for producing complicated cross sections. They are also energy and labor consumer. Extrusion, however, as an advanced manufacturing technique can produce cement composites with complicated cross sections while reduces energy and labor consumption. The process involves formation of highly viscous dough-like cement paste forced through a die with desired shape. As a continues process, extrusion is a suitable technique for industrial mass-production applications among which is fiber reinforced cement composites. Applying extrusion technique in manufacturing fiber reinforced cement composites has been studied by different researchers. In Hong Kong, Zongjin Li et al produced different extrudates such as cylindrical shape, panels, sheets, and honeycomb whose mechanical properties such as tensile and flexural strength showed significant improvements compared to the cast specimens.

\section{EXPERIMENTAL PROCESURES:}

Materials. The main components of HVFA extrudates were ordinary Portland cement (type I), fly ash (class F), expanded Perlite as coarse aggregate ,PVA fiber, superplasticizer (ADVA Grace 105 ), rheology modifier (METHOCEL ${ }^{\mathrm{TM}}$ cellulose ethers),paraffin (Rubitherm ${ }^{\mathrm{TM}} 27$ ) as phase change material and water. The spherical morphology of fly ash is beneficial for better workability. In addition high volume of fly ash in mix proportion reduces overall heat of hydration as well as rate of heat generation which prolong plastic properties of paste required for extrusion.

The PVA fiber used in the experiment is from Kuraray, Japan whose length is $8 \mathrm{~mm}$ and diameter is 12 microns. The chemical compositions of binder and aggregate are represented in table 1 .

Table 1. Chemical Compositions of Binders and Aggregate (\%)

\begin{tabular}{|c|c|c|c|}
\hline Composition & Portland Cement & Fly Ash & Expanded Perlite \\
\hline $\mathrm{SiO}_{2}$ & 22.30 & 49.05 & 75.9 \\
\hline $\mathrm{Fe}_{2} \mathrm{O}_{3}$ & 2.48 & 9.98 & 0.69 \\
\hline $\mathrm{Al}_{2} \mathrm{O}_{3}$ & 3.80 & 19.63 & 13.05 \\
\hline $\mathrm{MgO}$ & 2.25 & 4.96 & - \\
\hline $\mathrm{CaO}$ & 62.70 & 9.85 & 0.97 \\
\hline $\mathrm{Na}_{2} \mathrm{O}$ & 0.39 & 1.21 & 4.53 \\
\hline $\mathrm{K}_{2} \mathrm{O}$ & 1.96 & 1.77 & 0.65 \\
\hline $\mathrm{TiO}_{2}$ & - & 0.89 & 0.15 \\
\hline $\mathrm{MnO}_{\mathrm{SO}}$ & - & 0.18 & -06 \\
\hline
\end{tabular}

Preparation of PCM composites. EP/PA composites (PCM composites) used for this study were fabricated by direct incorporation method[Sun 2013 , Lu 2014].Paraffin was first molten in an oven at 60 ${ }^{\circ} \mathrm{C}$ and then mixed with expanded perlite (with 1:1 mass ratio) immediately at room temperature and put back to oven. The mixture was remixed every one hour for several times until uniformly dispersion of paraffin in expanded perlite formed the EP/PCM composite. 
Mix Proportion and extrusion of HVFA. For HVFA extruded panels different mix proportions were chosen based on many mix trials and extrusions listed in table 2. Effect of fiber volume, aggregate content (e.g, expanded perlite) and phase change material on mechanical and thermal properties of extruded panel were investigated.

To obtain fresh paste with good workability and extrudability, the raw materials were first dry mixed for 3 minutes and water was then gradually added to the mixture .PVA fibers were added after formation of paste .The dough-like paste was then fed into single-screw with a die-land of $110 \mathrm{~mm}$ width and $20 \mathrm{~mm}$ thickness in order to manufacture rectangular panels.

Table 2. Mix Proportions of Extruded Panels (mass \%)

\begin{tabular}{|c|c|c|c|c|c|c|}
\hline Component & HVFA1 & HVFA1/PCM & HVFA2 & HVFA2/PCM & HVFA3 & HVFA3/PCM \\
\hline Fly Ash & 35 & 33 & 35 & 33 & 36 & 35 \\
\hline $\begin{array}{c}\text { Portland } \\
\text { Cement }\end{array}$ & 25 & 23 & 25 & 23 & 26 & 25 \\
\hline $\begin{array}{c}\text { Expanded } \\
\text { Perlite }\end{array}$ & 6 & 6 & 6 & 6 & 4 & 4 \\
\hline Fiber* & 0.6 & 0.6 & 1 & 1 & 1 & 1 \\
\hline W/binder & 0.19 & 0.18 & 0.18 & 0.16 & 0.18 & 0.15 \\
\hline
\end{tabular}

*Volume \%

Thermal Test. Extruded specimens with $200 \mathrm{~mm}$ length , $110 \mathrm{~mm}$ width, and $20 \mathrm{~mm}$ thickness were examined for thermal conductivity test schematically shown in figure 1.As it is seen the box is thermally insulated by $b$ foam board and the specimen is fixed on the holder. To determine the thermal behavior of specimen, a sensor is attached to its center. An infrared lam with $275 \mathrm{~W}$ serves as thermal radiation source .During test, specimen was under thermal radiation for 4 hours (steady thermal test) and the temperature of inner and outer surfaces were measured and recorded by a multi-channels data logger.

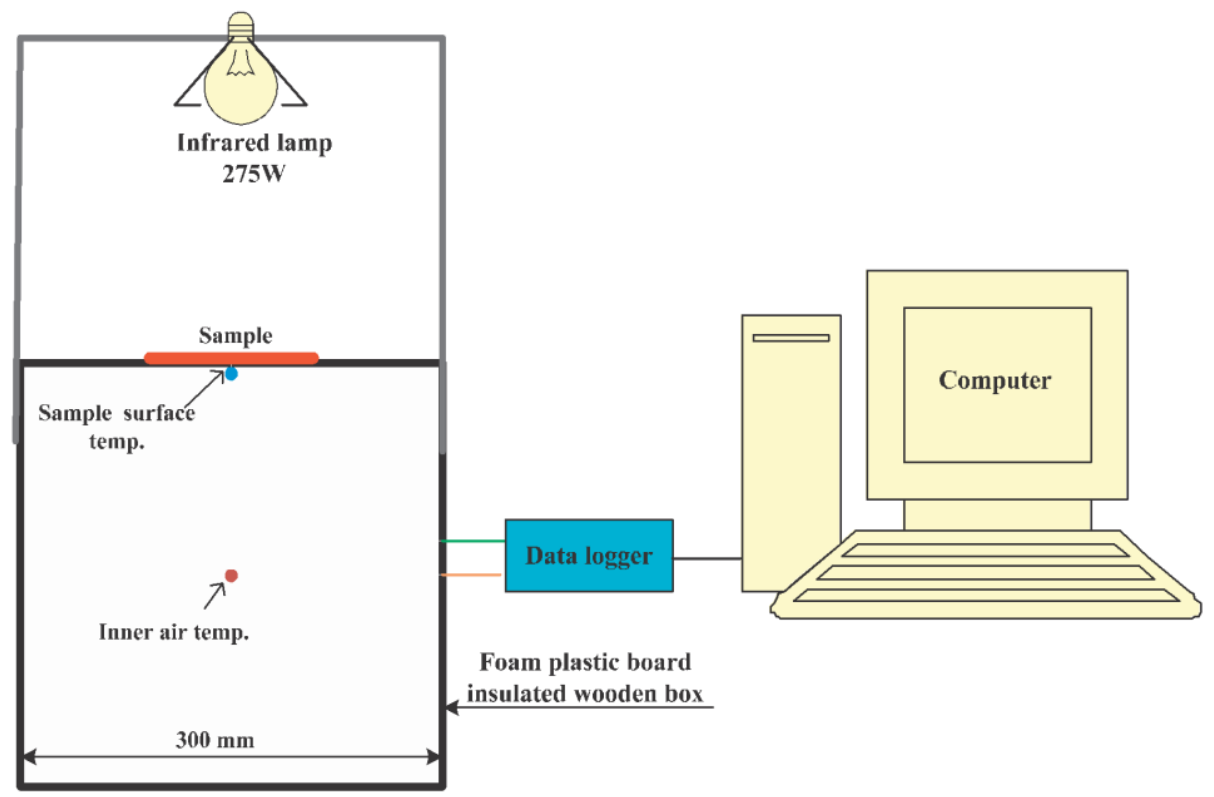

Figure 1. Steady Thermal Test Set up 
Mechanical test. In order to measure bending strength of extruded specemins, 4 points bending test was conducted for specimen with dimension of $250 \mathrm{~mm} \times 110 \mathrm{~mm} \times 19 \mathrm{~mm}$. (after 28 days steam curing time). The loading and support spans were $75 \mathrm{~mm}$ and $225 \mathrm{~mm}$ respectively .Two LVDT (Linear Variable Differential Transformers) were connected to each side of specimen to measure the deflection at mid-point. The flexural strength can calculated based on equation 1:

$\sigma=\frac{F L}{b t^{2}}$

In this formula, $\mathrm{F}$ is load at which fracture occurs, $\mathrm{L}$ is support span, $\mathrm{b}$ and $\mathrm{t}$ are width and thinness of specimen ,respectively.

\section{RESULTS AND DISCUSSION:}

Characterization of EP/PCM Composite. Figure 2 shows the SEM image of EP and EP/PCM composites. Comparing these two images indicates that PCM can well cover the pores of perlite. In addition, in order to make sure that there is no chemical reaction between PCM and EP, FTIR was performed on EP, PCM and EP/PCM composite whose results is shown in figure 3.

Based on the FTIR spectroscopy technique, main peaks of EP, PCM are remain unchanged in EP/PCM composite indicating that there is just physical interaction (i.e., capillary forces between EP and PCM ). This makes Paraffin a good candidate for fabricating PCM composite.

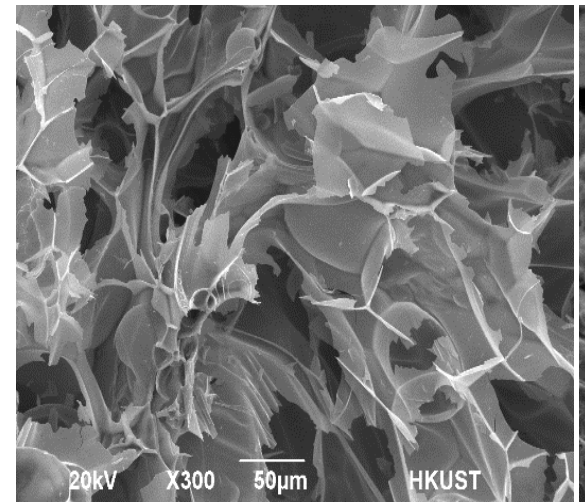

(a)

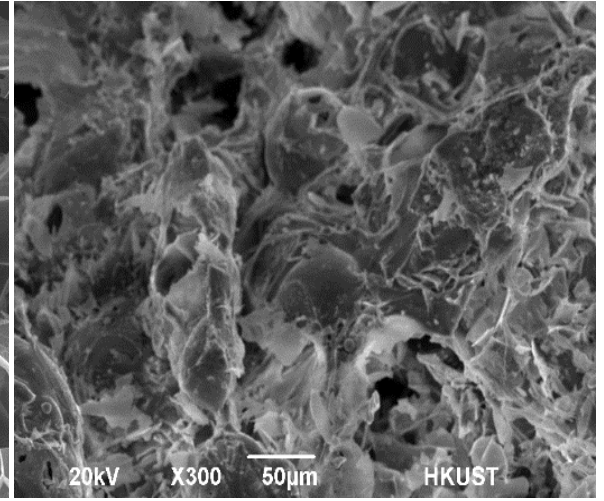

(b)

Figure 2. a) SEM micrograph of EP, and b) SEM micrograph of EP/PCM composites

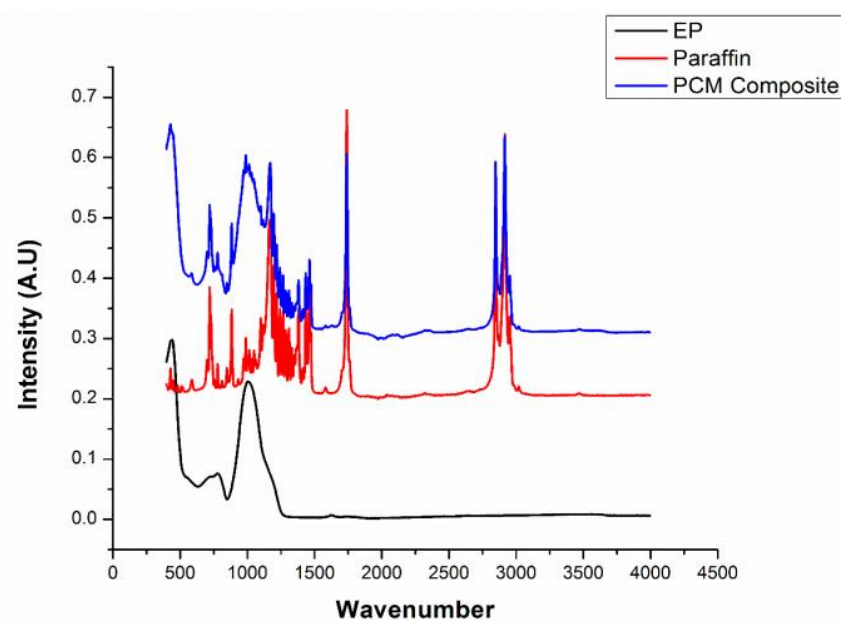

Figure 3. FTIR spectra of EP, PCM, and EP/PCM composite 
Thermal Stability of EP/PCM Composite. TGA technique was applied for evaluation of thermal stability of fabricated EP/PCM composite.AS it is shown in figure $4 \mathrm{EP} / \mathrm{PCM}$ composite is stable at temperature above normal daily life temperature and start to lose weight at around $125^{\circ} \mathrm{C}$.

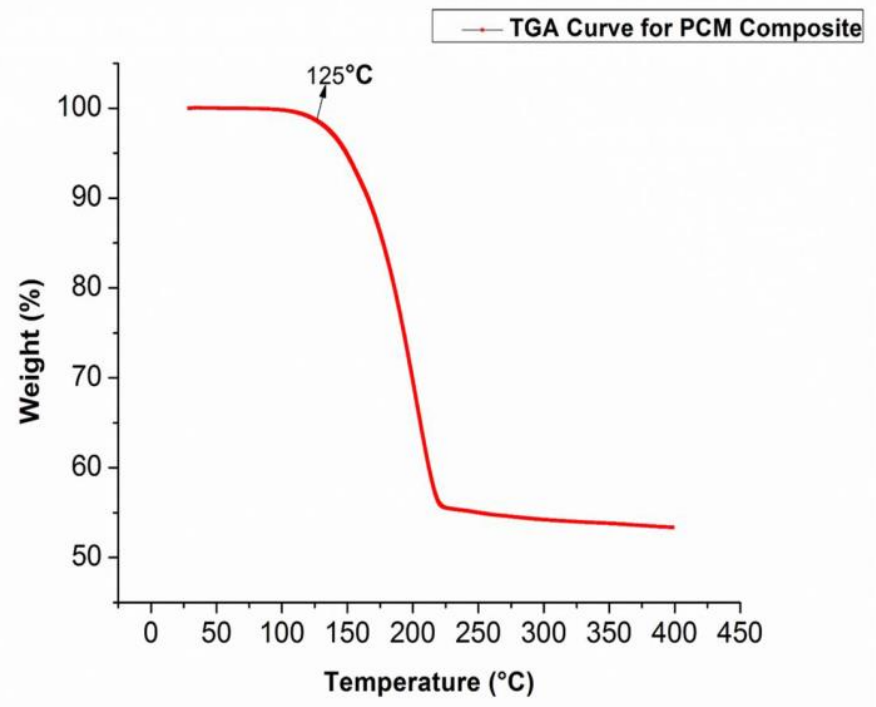

\section{Figure 4. TGA analysis of fabricated EP/PCM composite}

Effect of Phase Change Material on thermal storage property of Extruded Panels. Figure 5 Illustrates the temperature difference between inner and outer surfaces of extruded panels with different in expanded perlite content under steady thermal test. As shown, increasing volume fraction of expanded perlite leads to higher temperature difference .(e.g., HVFA2 and HFFA3 ).Moreover, incorporating PCM with perlite enhances temperature difference indicating EP/ PCM composites serves well in the extruded specimens.

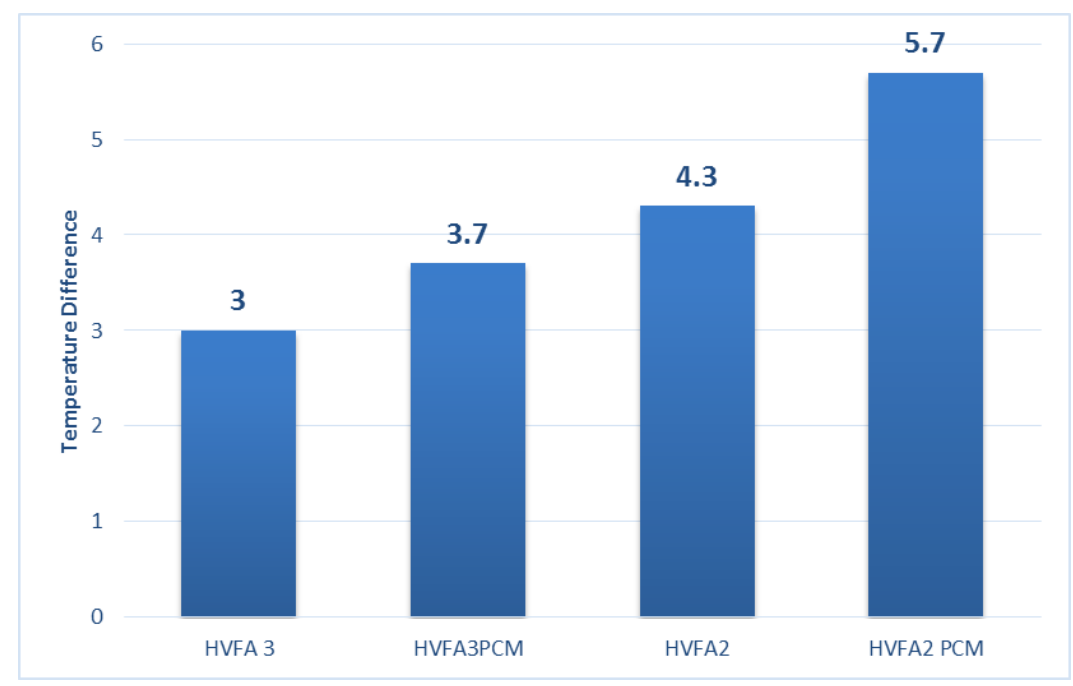

Figure 5. Temperature difference between inner and outer surface of specimens under thermal test 
Mechanical Properties of Extruded Panels. Table 3 lists experimental results of flexural strength, first crack strength, and mid-point deflection of extruded specimens. Based on these results, in three studied series mid-point deflection of specimens containing PCM is higher than the same composites without PCM.

Figure 6 and figure 7 show load versus mid-point deflection curves of studied specimens in four-points bending test. It is obvious that paraffin incorporation results in flexural strength reduction, while flexural toughness improves. This effect can be attributed to the fact that paraffin dilutes matrix and reduces its strength, as a result, first crack occurs at a lower stress. In addition, if the applied load is big enough ,multiple cracks will form. Li et al [Li 2013] investigated the effect of matrix strength on flexural strength of cement based composites and found that the lower strength of matrix is, the higher flexural strength will be. Moreover, paraffin decreases fiber/matrix interfacial bonding ,consequently, load carrying capacity of cement composite will decline which will further help in reducing total flexural strength of specimen.

On the other hand, fiber alignment caused by applied shear forces during extrusion process can control and arrest micro-cracks via bridging mechanism . This will allow stresses to be transferred back into the matrix and makes more micro-cracks which will finally enhances toughness of composites and this is one of the main advantages of extrusion technique in producing fiber reinforced cement composites. Thus, the paraffin and fiber incorporation has the potential for toughness improvement in fiber reinforced extruded panels.

Table 3. Flexural Strength, Frist Crack Strength, and Mid-Point Deflection of Specimens

\begin{tabular}{|c|c|c|c|}
\hline Specimen & $\begin{array}{c}\text { Flexural Strength } \\
(\mathrm{MPa})\end{array}$ & $\begin{array}{c}\text { First Crack Strength } \\
(\mathrm{MPa})\end{array}$ & $\begin{array}{c}\text { Mid-Point Deflection } \\
(\mathrm{mm})\end{array}$ \\
\hline HVFA1 & 5.5 & 4.82 & 1.2 \\
\hline HVFA1/PCM & 3.7 & 3.55 & 2 \\
\hline HVFA2 & 9.63 & 6.81 & 2.28 \\
\hline HVFA2/PCM & 8.13 & 5.78 & 1.74 \\
\hline HVFA3 & 8.46 & 8.36 & 3.36 \\
\hline HVFA3/PCM & 7 & 5.93 & \\
\hline
\end{tabular}

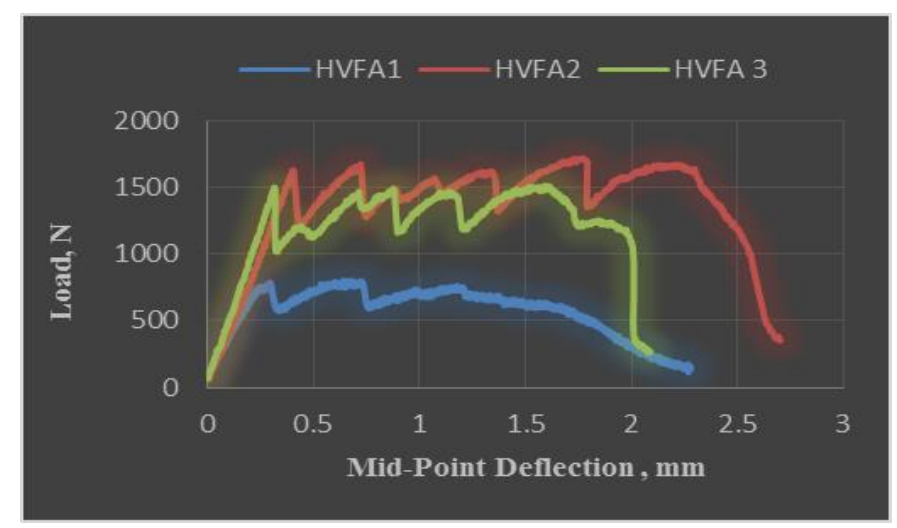

Figure 6. Load-Deflection for extruded specimens 


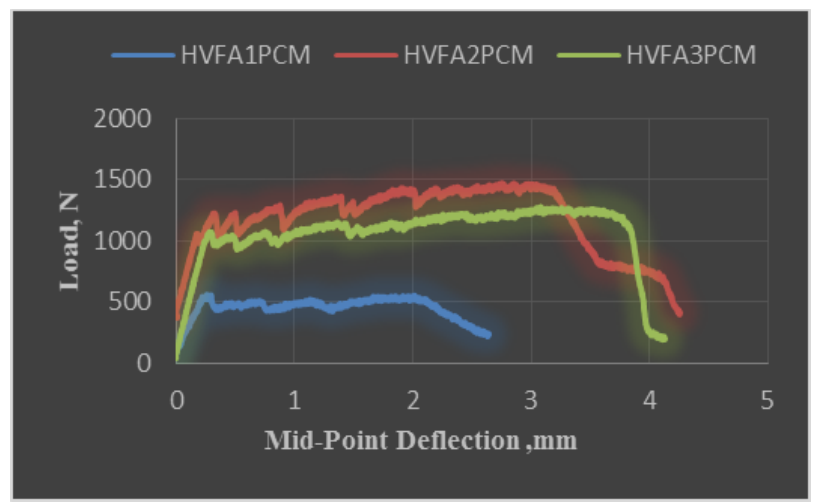

Figure 7. Load-displacement for extruded specimens containing PCM

\section{CONCLUSION}

1- The TGA and SEM images revealed that the EP/PCM composites fabricated by direct incorporation method is uniform and stable at normal daily temperature.

2- The EP/PCM composite incorporation can enhance thermal insulation property of extruded panels as temperature difference between inner and outer surface increased by PCM incorporation in specimens.

3- Although PCM incorporation reduces flexural strength of cement composites, extrusion technique due to fiber alignment can compensate this drawback and improves the ductility of panel.

4- The HVFA2PCM showed the best thermal insulation behavior with satisfied mechanical property to be used for structural member and has the potential to be used as a sustainable construction materials.

\section{REFERENCES}

E. Gartner (2004), industrially interesting approaches to "low-CO2" cements, Cement and Concrete Research, 34 1489-1498

J.I. Bhatty, F. MacGregor, S.H. Kosmatka (2004). "Innovations in Portland cement manufacturing" Portland Cement Association, Skokie, Illinois, U.S.A.

J.S. Damtoft, J. Lukasik, D. Herfort, D. Sorrentino, E.M. Gartner(2008),

Sustainable development and climate change initiatives, Cement and Concrete Research, 38 115-127

Li WQ, Qu ZG, Zhang BL, (2013) Thermal behavior of porous stainless-steel fiber saturated with phase change material. Energy;(55)- 846-52.

Lu Z, Xu B, Zhang J, Zhu Y, Sun G, Li Z. [2014]. Preparation and characterization of expanded perlite/paraffin composite as form-stable phase change material. Sol Energy;108:460e6.

Sun D, Wang LJ, Li CM.(2013), Preparation and thermal properties of paraffin/ expanded perlite composite as form-stable phase change material. Mater Letters (108) 247-9.

U.S. Geological Survey (2015), Mineral Commodity Summaries, at http://minerals.usgs.gov/minerals/pubs/commodity/cement/mcs-2015-cemen.pdf 